\title{
How does storytelling within higher education contribute to the learning experience of early years students?
}

\section{Sarah Flanagan}

\begin{abstract}
Background and rationale. Reading stories telling stories is a familiar practice within primary education; furthermore there is recognition that stories are used within higher education. This study seeks to understand how storytelling within higher education contributes to the learning experience of early years students. It is anticipated that a deeper understanding of stories and storytelling in this context will lead to a greater appreciation of this resource and its enhanced use.

Design/methods. A qualitative methodology was used. The participants included 45 early years students. All students involved in the study were employed as early years workers contributing to the care and education of children aged 0-5. Semi structured interviews and non-participant observations were completed to collect the data and thematic analysis was used in its interpretation.

Findings. Participants saw multiple contributions of story and storytelling including the facilitation of learning, the enhancement of reflective practice and the reinforcement of professional/group culture. Story and storytelling provided opportunities for relaxation, entertainment and had a significant social impact. Certain activities encouraged storytelling and the most engaging stories were those that the listener could relate to.
\end{abstract}

Keyword: story and storytelling; reflection; learning; culture

1. Senior lecturer, Institute of Childhood and Education

Address for correspondence: Leeds Trinity University. Brownberrie Lane. Horsforth, Leeds, LS18 5HD. s.flanagan@leedstrinity.ac.uk 


\section{Introduction}

There is recognition that stories are useful within higher education particularly in the areas of reflective practice and professional development (McDrury and Alterio, 2002; Moon, 2010; Harrison, 2009). Numerous benefits of story have been identified including the enhancement of self-knowledge (Taylor, 2006) and the facilitation of student development (Alterio, 2004). Storytelling was also found to improve collaborative working (Gold and Holman, 2001). This study aims to build on the work of previous researchers by exploring how early years students value the contribution of storytelling to their learning experience.

The research question is: How does storytelling within higher education contribute to the learning experience of early years students?

Questions contributing to the main research question are:

- What is the role of story and storytelling?

- How are links between story storytelling and reflective practice perceived by the students?

- What is the impact of story and storytelling on social activity within the classroom?

- How is storytelling encouraged, are there reoccurring themes in stories shared and what are the ingredients of an engaging story?

Despite the different origins within language (Frid, Öhlén and Bergbom, 2000) writers studying story as a concept often use the words narrative and story interchangeably (Bruner, 1986; Webster and Mertova, 2007; Moon, 2010). There is an appreciation that story and narrative are closely linked (Frid, Öhlén and Bergbom 2000; Webster and Mertova, 2007). For the purpose of this study the words story/ storytelling will be used. The word story will encompass case studies, critical incidents, scenarios, anecdotes and narratives from official documents.

Teaching and learning strategies used within higher education do have an impact on the early years profession. Recently there has been an increased emphasis on developing the academic attainment of this group which can lead to enhanced provision (Nutbrown, 2012). Morgaine (1999) concluded that higher education provided early years workers with opportunity to enhance their reflective and analytical skills.

The participants in the study are a small group of early years workers involved in the completion of the Foundation Degree Young Children's

147 J. of Practice Teaching \& Learning 13(2-3), pp.146-168. @ w\&b 
Learning and Development. This foundation degree offers modules specifically related to professional development: here reflective practice including reflective thinking and writing are encouraged.

The study is exploratory in its nature. It seeks to understand the opinions and views of those involved and it therefore takes a qualitative approach. Background theory will include theories exploring the association between story and learning, the concept of story, story's links to reflective practice, the cultural and social connections to story and storytelling, reoccurring themes and the ingredients of an engaging story. The methods chosen are semi-structured interviews and non-participant observations. Extracts from the collected data will be included in the findings to support the accompanying analysis. The study will conclude with a discussion of the findings and recommendations.

\section{The literature review}

\section{Story, storytelling and adult learning}

The constructivist view of learning accepts new concepts are accommodated within an individual's cognitive structure 'what we know understand and feel at any given time' (Marton and Booth, cited in Moon, 2010, p.34). Stories are particularly valuable within this learning process for a number of reasons. Learning is achieved through deliberation (Moon, 2010). Stories can capture people's attention through their narrative structure (Bruner, 1986) therefore concepts contained within a story have a greater chance of being noticed and possibly accommodated. Stories also introduce new experiences and perspectives to a person's cognitive structure even without the listener having to be present at the actual event (Bruner, 1986). The emotive qualities of story and the existence of the cognitive structure demonstrates how an individual can make a connection to a story and accommodate it both intellectually and emotionally (Chan and Chung, 2004).

\section{The concept of story}

Story has a number of uses. It is used to 'organise our experiences into tales

148 J. of Practice Teaching \& Learning 13(2-3), pp.146-168. @ wE-b 
of important happenings' (Webster and Mertova, 2007:10). Story allows expression of an individual's perception of the world they inhabit (McDrury \& Alterio, 2002). It is seen as fundamental to a person's understanding of their day to day experience (Bruner 1987, 1991). Ricoeur uses the concept of time to illustrate this point he states that we use narrative to structure and sequence time (1984, 1990).

Story commonly refers to the timeless plights of human experience which usually unfold in the form of the plot (Bruner, 1987). The plot often contains references to time, place, events and the individuals involved. Story is usually concerned with discordance and concordance here the sense of harmony is disrupted and regained (Bruner, 1987; Ricoeur, 1990).

A relationship exists between the narrator or reader of a story and the listener, neither are passive in the process. (Ricoeur, 1990; Bruner, 1986 and Boje, 1991) As the narrator offers their interpretation of the story the listener recreates the events for themselves through their own imagination. There can be differences in what is mentioned explicitly during a story and its overall meaning (Bruner, 1986) this allows a story to deliver a message.

The presence of certain characteristics within story suggests that they are recognisable. This means people may respond to a story in a certain way because they know it is a story. The social nature of story is also revealed.

Often stories are perceived as factual or as products of the author's imagination (Gabriel, 2000). However different categories of story can often overlap (Moon and Fowler, 2008). Ricoeur (1990) is reluctant to place too much emphasis on the categorisation of stories. He states that the difference between stories perceived as factual and those viewed as fiction is not as distinct as it may appear.

The debate surrounding the categorization of stories and the mingling of fact and fiction is relevant to higher education. The categorisation of a story appears to impact on its use. For example stories used in the training of professionals such as early years workers are often reflective accounts. These accounts generally contain descriptions of students' activities within the workplace. They are usually perceived as accurate and the activities described are judged against the standards prescribed by that profession (Taylor, 2006). However these stories like all others are an individual's reinterpretation of events influenced by the storyteller's cognitive structure. To judge reflective accounts purely by their authenticity and their ability to demonstrate practice within prescribed standards could be oversimplifying their value. Taylor (2006) explored this issue during her study of reflections written by social work students. Taylor stated it was naïve to believe that 
written extracts were 'what really happened in any given situation' (p.194). She maintained students wrote what they chose to write. Significantly Taylor states this does not mean that such accounts should be dismissed as lies and distortions but they should be seen for what she believes is their true value: examples of how students developed their professional identity through their portrayals of how they hoped to be or thought they should be.

\section{Story and its relationship with reflective practice}

Reflection is essentially thinking about and re- examining events (McDrury and Alterio, 2002). Schön (1983) believed that reflection was crucial to the development of professional practice. He concluded that the knowledge which evolved through reflective practice was a form of informal theory. Schön's hypothesis has led to greater use of modules promoting reflection within higher education particularly on vocational courses (Harrison, 2009).

McDrury and Alterio (2002) emphasise the role story has within reflective practice, that it is used in both reflective thinking and writing. McDrury and Alterio advocate the use of pre-planned stories to enhance and stimulate reflection. The close association between story and reflection fits with the views of Bruner (1987) and Ricoeur (1984) that story is not simply retelling events it is an opportunity for reinterpretation and greater understanding. There are considered to be different depths of reflection. Deeper reflection involves participants examining alternative perspectives and external influences (Bain et al, 1999; Fund, Court and Kramarski, 2002).

In addition to the exploration of alternative perspectives encouraged by story sharing (McDrury and Alterio, 2002) story also brings an emotional element to reflections (Douglas and Carless, 2009; Chan and Chung, 2004; McEwen and Egan, 1995). Given this opportunity to consider emotions students could develop a greater understanding of their feelings. Noddings (1996) states the emotional responses evoked in stories can reduce a student's sense of isolation as they recognise similar responses in their peers.

\section{The social impact of story}

The social aspect of storytelling appears to fulfil numerous functions. Stories

150 J. of Practice Teaching \& Learning 13(2-3), pp.146-168. @ w\&b 
encourage a sharing of ideas and experiences which contribute to group cohesion. They provide enjoyment through their capacity to entertain (Moon, 2010). Stories are thought to encourage human interaction as conversation is encouraged through story trading (Schank, 1995). Physiological studies have been conducted supporting the notion of a close relationship between story and social activity. These studies found storytelling and their understanding connected to the part of the brain associated with social processing (Lieberman, 2007; Saxe and Wexler, 2005).

One area of social activity that has been particularly linked to story is that of culture.

Schein (1987) states;

Culture is a pattern of shared basic assumptions, invented, discovered or developed by any given group as it learns to cope with its problems of external adaptation and internal integration that has worked well enough to be considered valid, and therefore is taught to new members of the group as the correct way to think and feel in relation to those problems -re-framing. (p.31)

Schein's definition is relevant for this study as Schein claims any group in any given context such as a group of learners studying together has a culture. Bruner (1990) also links culture to a set of assumptions that influence people's behaviour. He maintains that one of the main ways these set of assumptions are formed is through 'Folk Psychology' (p.35). 'a set of more or less connected, more or less normative descriptions about how human beings tick' (p.35). He adds folk psychology is usually referred to as common sense. Bruner maintains common sense implicitly influences people's views on what is and is not reasonable and that humans learn common sense through story. Their collection of stories guides their understanding of situations including identification of the unusual and the acceptable. To try and make sense of a new situation a repertoire of stories is used.

\section{The ingredients of an engaging story/storytelling}

Stories contain characters and plots. They have a combination of the familiar and the unfamiliar, often recalling how the status quo is disrupted and regained. Taylor Fisher and Dusfresne (2002) add that interesting stories possess interesting characters, language and settings and they provide insights

151 J. of Practice Teaching \& Learning 13(2-3), pp.146-168. ๑ w\&b 
into human activity. Propp (1968) concluded that fairy stories handed down over many years possessed repetitive, ready-made formulae. It appears that certain kinds of experiences traditionally lend themselves to producing an interesting story. Given the close connection between culture and story details are likely to vary from one culture to another (Moon, 2010). Numerous authors acknowledge the relevance of the storyteller to the quality of the story (Taylor, 2006; Wooffitt, 1992; Moon, 2010; McDrury \& Alterio, 2002).

\section{Methodology}

The design and approach. The aim of the study is to achieve greater comprehension of how storytelling within higher education contributes to the learning experience of early years students. The study is based on the ontological perspective that human beings are unique individuals and reality can be the result of 'individual cognition' (Cohen, Manion and Morrison, 2000. p.5). As the study's prime concern is the views and opinions of those involved it is underpinned by an interpretative paradigm (Cohen, Manion and Morrison, 2000). The qualitative approach to research was chosen for this study because the qualitative approach is exploratory in its nature; and prioritises a depth of understanding (Robson, 2002) This approach is also generally associated with the interpretative paradigm (Walliman, 2005)

The participants there were 45 students, all female, who participated in the study. The age range of participants was eighteen to mid-forties. All were employed within the early years field .They represented three learning groups. Each group was at a different stage of the foundation degree. The three groups had a similar employment and age profile to all other groups on the course. The three groups contributing to the research did so in response to a request for volunteers. Five of the students were interviewed and observed the remaining student volunteers were observed only.

Data collection- As the research approach was qualitative; methods associated with the qualitative approach were used. Semi structured interviews were conducted. Five interviews were completed in total. All interviews were audiotaped and transcribed.

The other method of data collection used for this study was observations. They were chosen for their effectiveness in supporting interviews (Robson, 2002) . They also provided opportunity to observe everyday activities

152 J. of Practice Teaching \& Learning 13(2-3), pp.146-168. @ w\&b 
(Silverman, 2006) including social interaction and the spontaneous nature of any storytelling that occurred.

Descriptive records of the observations were made in the form of field notes in addition to audio recordings as recommended by Silverman (2006). Audio recording was thought to be particularly useful to this subject as it would capture content of any spontaneous story telling events. The researcher was interested in what encouraged story and its consequences. Recording lessons would also offer detail of this process. The results of the observations were transcribed initially as a narrative illustrating the general themes of the observation and any storytelling. These narratives were then transferred to summary tables showing the antecedent to a story and its consequences. Five observations were completed in total.

Analysis- Thematic analysis was used to establish the dominant themes emerging from the collected data. Data from the interview transcripts was initially categorised according to the research questions as recommended by Drever (2003). This data was then examined for initial codes which were collated and collected into themes as advocated by Wilkinson (2000), and Braun and Clarke (2006). Patterns of storytelling captured in the observations were also coded and categorised in relation to the research questions. As the researcher was analysing the sequence and impact of the storytelling process particular attention was paid to the antecedent to a story and its consequences. The researcher is aware that a particular focus on the antecedent to story and consequences within the observation involves some filtering of information (Bell, 2010)

Data presentation- Data from the semi structured interviews is presented in relation to the main findings and categories. It will take the recommended form of abstracts from the interviews (Clough and Nutbrown, 2007). Table 1 summarizes the results of observations.

\section{Validity and Reliability}

Construct validity- the researcher has made explicit the approach to the study. Existing literature has been cited to demonstrate understandings of the phenomena to be studied. Methods of data collection have been identified that are linked to qualitative approaches. Methodological Triangulation as advocated by Yinn (2003) has been used to 'cross check individual accounts and build up a body of evidence' (Bond, 2006:131).

153 J. of Practice Teaching \& Learning 13(2-3), pp.146-168. @ w\&-b 
The study's construction prioritises transparency for example transcripts were available to participants. Details including context, overall aims of the study and the underlying principles have been made explicit in order to meet the requirements of external validity and reliability (Cohen, Manion and Morrison, 2000).

\section{Ethics}

To specifically meet the ethical obligations of this study an ethics protocol was written and given ethical approval by the university. Attention was given to ensuring informed consent and protecting the identity of participants. The study was seen as generally low risk however the researcher acknowledged that given the emotive nature of storytelling participants may wish to withdraw from the project and they were informed that they could do so at any time.

\section{Analysis and findings}

Table 1 overleaf illustrates a summary of all storytelling activity that occurred within the 5 lectures observed, including precipitating events, the nature and impact of the story. 
Table 1: Summary of observations - Lectures 1,2,3,4,5,

\begin{tabular}{|c|c|c|}
\hline & Lecture 1 & \\
\hline Antecedent to story & Story & Consequences \\
\hline $\begin{array}{l}\text { T comments about } \\
\text { playing out as a child }\end{array}$ & $\begin{array}{l}\text { SWR story about } \\
\text { parent's response to } \\
\text { children playing outside }\end{array}$ & $\begin{array}{l}\mathrm{T} \text { asks for examples of } \\
\text { risky behaviour when } \\
\text { students were children }\end{array}$ \\
\hline $\begin{array}{l}\text { SPER examples of risky } \\
\text { behaviour and laughter }\end{array}$ & $\begin{array}{l}\text { SPER story of risky } \\
\text { behaviour }\end{array}$ & $\begin{array}{l}\mathrm{T} \text { asks questions in } \\
\text { relation to story }\end{array}$ \\
\hline $\begin{array}{l}\text { Statement from } \mathbf{T} \text { that } \\
\text { peer pressure occurs in } \\
\text { early childhood }\end{array}$ & $\begin{array}{l}\text { PER story from } \mathrm{S} \\
\text { about her child's risky } \\
\text { behaviour }\end{array}$ & $\begin{array}{l}\text { S Supportive comments } \\
\text { from group }\end{array}$ \\
\hline $\begin{array}{l}\mathrm{T} \text { introduces topic of } \\
\text { partnership working }\end{array}$ & $\begin{array}{l}\text { WR story from } \mathbf{T} \text { on } \\
\text { partnership working }\end{array}$ & $\begin{array}{l}\text { T reinforces her point } \\
\text { with comment }\end{array}$ \\
\hline $\begin{array}{l}\text { T quotes from literature } \\
\text { re: partnership working }\end{array}$ & $\begin{array}{l}\text { PER story from S re: } \\
\text { her own child's varying } \\
\text { behaviour }\end{array}$ & $\begin{array}{l}\text { S Supportive comments } \\
\text { from group }\end{array}$ \\
\hline $\begin{array}{l}\text { S comments about } \\
\text { children's varying } \\
\text { behaviour }\end{array}$ & $\begin{array}{l}\text { WR story from } \mathbf{S} \\
\text { about babies changing } \\
\text { behaviour }\end{array}$ & $\begin{array}{l}\text { PER story from } \mathbf{S} \text { about } \\
\text { her child's varying } \\
\text { behaviour, laughter }\end{array}$ \\
\hline $\begin{array}{l}\text { T request s strategies for } \\
\text { addressing children's } \\
\text { behaviour }\end{array}$ & $\begin{array}{l}\text { WR story detailing } \\
\text { strategies }\end{array}$ & $\begin{array}{l}\text { SWR story detailing } \\
\text { strategies }\end{array}$ \\
\hline T summarises & $\begin{array}{l}\text { PER story from } \mathrm{T} \text { re: } \\
\text { boundaries }\end{array}$ & $\begin{array}{l}\text { T changes direction of } \\
\text { lecture }\end{array}$ \\
\hline \multirow[t]{2}{*}{$\begin{array}{l}\text { Question from T re: } \\
\text { cleanliness }\end{array}$} & $\begin{array}{l}\text { WR story from } \mathbf{T} \text { re: } \\
\text { hygiene }\end{array}$ & $\begin{array}{l}\text { TS Laughter plus } \\
\text { cleaning examples }\end{array}$ \\
\hline & Lecture 2 & \\
\hline $\begin{array}{l}\text { Request from } \mathrm{T} \\
\text { for examples of } \\
\text { guest speakers who } \\
\text { demonstrate hygiene }\end{array}$ & $\begin{array}{l}\text { SWR story re: speakers } \\
\text { from a zoo }\end{array}$ & S animal story \\
\hline $\begin{array}{l}\text { T comment re: family } \\
\text { life style }\end{array}$ & SWR story re: diet & T supportive comment \\
\hline $\begin{array}{l}\mathrm{S} \text { comment re: } \\
\text { moderation in cleaning }\end{array}$ & $\begin{array}{l}\text { SWR story re: criticism } \\
\text { from Ofsted re: Soap }\end{array}$ & $\begin{array}{l}\text { T PER story re: } \\
\text { moderation in cleaning }\end{array}$ \\
\hline $\begin{array}{l}\text { TS Discussion re: } \\
\text { environment and health } \\
\text { services }\end{array}$ & WR story from $T$ & T summarises \\
\hline
\end{tabular}




\begin{tabular}{|c|c|c|}
\hline $\begin{array}{l}\text { T invites examples } \\
\text { of responses to } \\
\text { emergencies }\end{array}$ & $\begin{array}{l}\text { SWR story re: baby who } \\
\text { had a convulsion }\end{array}$ & $\begin{array}{l}\mathrm{T} \text { comments about the } \\
\text { need for emergency } \\
\text { procedures }\end{array}$ \\
\hline $\begin{array}{l}\text { TS Discussion re: first } \\
\text { aiders }\end{array}$ & $\begin{array}{l}\text { SWR story of a lost } \\
\text { child }\end{array}$ & $\begin{array}{l}\text { S Comments from } \\
\text { students }\end{array}$ \\
\hline \multirow{2}{*}{$\begin{array}{l}\text { Statement from } \mathrm{T} \text { the } \\
\text { worst thing in a setting } \\
\text { is to lose a child }\end{array}$} & $\begin{array}{l}\text { SWR story of a lost } \\
\text { child }\end{array}$ & $\begin{array}{l}\text { SWR story of child } \\
\text { running away }\end{array}$ \\
\hline & Lecture 3 & \\
\hline $\begin{array}{l}\text { T Introduces topic } \\
\text { of professional } \\
\text { development }\end{array}$ & $\begin{array}{l}\text { WR story from } \mathbf{T} \text { about } \\
\text { her early career }\end{array}$ & $\begin{array}{l}\text { S comments about } \\
\text { colleagues' reluctance to } \\
\text { change }\end{array}$ \\
\hline T Paired activity given & $\begin{array}{l}\text { PER story from } \mathrm{T} \text { re: } \\
\text { key people }\end{array}$ & $\begin{array}{l}\text { T requests career } \\
\text { changing examples }\end{array}$ \\
\hline T requests examples & $\begin{array}{l}\text { SWR story as feedback } \\
\text { from reflective activity } \\
\text { re: key people }\end{array}$ & Comment from $\mathbf{T}$ \\
\hline \multirow[t]{2}{*}{$\begin{array}{l}\text { Request from } \mathrm{T} \text { for } \\
\text { appraisal experiences }\end{array}$} & SWR story of appraisal & $\begin{array}{l}\mathrm{S} \text { comment re: role } \\
\text { models }\end{array}$ \\
\hline & Lecture 4 & \\
\hline $\begin{array}{l}\text { T instructs students on } \\
\text { the requirements of the } \\
\text { assignment }\end{array}$ & $\begin{array}{l}\text { TWR story about other } \\
\text { groups }\end{array}$ & $\begin{array}{l}\text { S comments re: } \\
\text { assignments }\end{array}$ \\
\hline T question re: modules & $\begin{array}{l}\text { SPER story of the child } \\
\text { development module }\end{array}$ & T supportive comments \\
\hline \multirow[t]{2}{*}{$\begin{array}{l}\text { T requests examples of } \\
\text { changes in assumption }\end{array}$} & $\begin{array}{l}\text { TWR story about a } \\
\text { student }\end{array}$ & $\begin{array}{l}\text { T changes focus onto } \\
\text { other aspects of the } \\
\text { assignment }\end{array}$ \\
\hline & Lecture 5 & \\
\hline $\begin{array}{l}\text { T Introduces learning } \\
\text { outcomes }\end{array}$ & TWR story about D.V.D. & $\begin{array}{l}\mathrm{T} \text { describes other } \\
\text { learning objectives }\end{array}$ \\
\hline$S$ break for tea & Story in D.V.D. form & \\
\hline
\end{tabular}

Abbreviations

$\mathrm{T}=$ Tutor; $\mathrm{S}=$ Student WR $=$ work related $; \mathrm{PER}=$ Personal 


\section{Research question one: What is the role of story and storytelling?}

Students identified three themes related to the role of story. These were: an association between story and the facilitation of learning, story offering opportunity for relaxation within lectures and story having a social function.

\section{Theme one: Story and the facilitation of learning}

Participants identified several ways that story facilitated learning particularly in relation to the transfer of information and knowledge. Participants felt stories generated knew ideas.

A student's comment:

You can take other people's ideas on board and think about how you can develop as an individual.

Participants believed that stories made new material easier to understand. This function of story was associated with a belief that stories helped learners identify recognisable features in new material which they could link to what they already know. These findings connect to the views of Boud and Walker (1993) that knowledge is accumulated through attachments to past experiences. They also support the constructivist theory of learning (Moon, 2010).

Students repeatedly emphasised how important story was in providing connections, they talked of stories relating and connecting to them: having meaning. Importantly this connection occurred intellectually for example through a familiar dilemma and or emotionally by recreating an emotional response from the past.

I think stories that are similar to something you have experienced or something that has happened to your setting. I think they in particular have an impact on you.

The power of stories to add interest to a lecture was attributed to their capacity to link theory and real life situations making the theory recognisable.

There was also acknowledgement that stories helped learners retain the material covered in lectures supporting the claims of Bruner (1990) and

157 J. of Practice Teaching \& Learning 13(2-3), pp.146-168. @ w\&b 
Moon (2010). The particular reason why individuals remembered stories was that they held meanings.

A student's statement:

We might remember the information they are trying to give us if they illustrate it with a personal point.

Students also connected the idea that stories illustrated a point with a belief that stories deliver a message.

Yes this is another way of delivering a message isn't it.

\section{Theme two: Story offering opportunity} for relaxation within lectures

Students commonly associated stories with laughter and fun. Their views fit with the idea that story has multiple purposes and one of its roles is as a source of entertainment and pleasure (Moon, 2010). Student comments were supported by the observations where laughter was often connected to storytelling (table 1).

\section{Theme three: Story having a social function}

When asked about the role of story and storytelling within higher education all interviewees acknowledged a social dimension to storytelling within this context.

\section{Research question two: How are links between story storytelling and reflective practice perceived by students?}

Two themes were identified in relation to this question. They were: story stimulates reflective practice and story enhances the quality of reflective practice.

158 J. of Practice Teaching \& Learning 13(2-3), pp.146-168. @ w\&b 


\section{Theme 1: Story stimulates reflective practice}

Students interviewed demonstrated a belief that stories stimulated reflective practice mainly through the encouragement of reflective thinking. Students described how their groups shared stories illustrating solutions to problems within the work place and during this process students recalled how they would assess the usefulness of strategies discussed to their own current or future dilemmas.

A student's comment:

If someone is relating a story it makes me think back to what has happened in my own work place or it makes me think of, you know how I could address a similar incident in the future.

It appears that story is an important tool for those activities requiring some scrutiny of the past such as reflective thinking. It is also apparent that the content and message contained within different stories can impact significantly on individuals: they see their own similar dilemmas and this triggers them to ponder their own experiences.

\section{Theme two: Stories enhancing the quality of reflective practice}

Students believed that there were different levels of expertise in reflective practice. Participants felt that the alternative perspectives and solutions generated by the sharing of stories not only stimulated reflective thinking but enhanced it. As recognised by McDrury and Alterio (2002).

The ability of stories to enhance reflective writing was mainly attributed to a perceived link between stories and theoretical models used on the course to promote reflective writing (Kolb, 1984; Gibbs, 1988)

Contrary to the views of McDrury and Alterio (2002) those interviewed made no differentiation between the usefulness to reflection of stories pre-prepared and stories that were triggered more spontaneously within the classroom. 


\section{Research question three: \\ What is the impact of story and storytelling on social activity within the classroom?}

All participants involved in the interviews recognised that story and storytelling had a social function within higher education. Their responses and the results of the observations developed into three themes.

They were: stories were seen to facilitate group cohesion. Stories contributed to and reinforced professional/group culture. Stories had some influence on the direction of learning.

\section{Theme one: Stories thought to facilitate group cohesion}

All students interviewed felt that stories made an important contribution to group cohesion. Examples of comments:

I think it brings the group together, I think it gels the group.

I think if we sat down and we just had our lecturers talking and we did not get involved don't think we would develop the relationship we have as a group.

The responses of participants indicated that they believed stories and storytelling facilitated group cohesion by the encouragement of sharing. Those interviewed connected sharing literally to the swapping of stories which was thought to generate ideas and new knowledge. This process of sharing of stories was seen frequently in the observations. Usually a story from one individual would generate a story from another (tablel).

I think sharing our stories has to have a positive impact it gives other people's feelings on a particular subject.

Interviewees also associated storytelling with sharing something of themselves.

It helps the lecturers understand a bit more about the person telling the story.

Many of the stories offered during the observations were personal rather than professional (table 1). Stories featured the children and

160 J. of Practice Teaching \& Learning 13(2-3), pp.146-168. @ w\&b 
childhood of group members and their history. These insights into the personal lives of the storytellers could be the reason why story sharing was linked to participants sharing something of themselves. Also as Moon (2010) and White (1991) suggested the very process of telling a story is in itself representing what a person knows and therefore simultaneously providing the listener with insights of the storyteller's internal experiences. (Ricoeur,1984).

The emotion created by story sharing also appeared to strengthen group cohesion. The physical signs of the emotion generated by story were well recognised by those interviewed. Laughter was associated many times with stories as was anger, frustration and sadness. During the observations laughter often occurred in response to a story (table 1). The display of emotions instigated by storytelling created empathy which may also have contributed to group togetherness.

A student's comment;

I think more of us are willing to tell stories but I think that's because. I think maybe some people, some of them have been quite emotional, in that they sort of impact on the class and then I think when you've gone past that sort afterwards, there's like a sort of rallying, supportive feeling.

\section{Theme two: Stories contributing to and reinforcing professional /group culture}

As Schein (1987) stated there are assumptions developed by any given group about the correct way to think and feel (their culture). There were several ways that culture influenced the content and responses to stories for participants within this study.

Students interviewed showed an awareness that there were implications to sharing stories about practice. They demonstrated a belief that they may be judged by the content of their stories. One way of approaching this belief was to limit or edit stories shared.

It's my one and only story because I like to listen but don't like to divulge too much because I think it's a small world and things travel round in terms of storytelling.

Another approach included building trust within the group. Again there was an indication that the group's cultural ideas about acceptable behaviour would influence the actual content of the story.

"I think because we know and trust each other we are more likely to be open about our experiences or even feelings, about what our real feelings would be: to really

161 J. of Practice Teaching \& Learning 13(2-3), pp.146-168. @ w\&b 
discuss them as opposed to what you should be feeling or think you should be feeling"

The blurring of fact and fiction in students' reflections and the influence of ideas about how things should be was explored by Taylor (2006). Taylor concluded this process was positive, that it made a valuable contribution to the development of professional identity.

This study provides insights into how story sharing reinforces and disseminates cultural ideas. The students stated they retained through storytelling potential solutions to possible problems. As discussed these stories are already subject to some cultural filtering possibly from more general ideas within the profession on acceptable behaviour. The stories obtained in higher education are retained in their narrative form along with others contributing to a collection of culturally influenced responses within the student's memory. As Bruner (1990) described a story is recalled when the student meets with a similar dilemma in the future along with other related stories. The student uses their memory to appraise their collection of stories and the one considered most appropriate will influence the response to this new situation. It is likely that at some point a story acquired during the higher education experience will be utilized in this way. The utilization of the story in this manner disseminates and reinforces the group's culture.

\section{Theme three: Stories have some influence of the direction of learning}

Students recognised that stories could influence the focus of the lesson and that telling a story can be empowering for the storyteller. This was seen in both a positive and a negative light. Story was seen to offer the opportunity for flexibility but could also allow lectures to lose focus. During the observations some stories told appeared unconnected to the precipitating event. This could lead to boredom and frustration.

A student's comment:

Sometimes they go off from what we have been discussing. I think people get sidetracked.

The potential difficulties involved in the inclusion of storytelling within higher education illustrate how storytelling requires careful management (Moon, 2010; McDrury and Alterio, 2002). The empowering nature of

162 J. of Practice Teaching \& Learning 13(2-3), pp.146-168. @ w\&b 
storytelling also suggests support for class members who do not feel they are natural storytellers.

\section{Research question four: How is storytelling encouraged, are there reoccurring themes in stories shared and what are the ingredients of an engaging story?}

Two themes were generated in response to this research question they were: particular events precipitated a story and interesting stories held meanings for individuals.

\section{Theme one: Particular events precipitated a story}

The broad themes of stories from both the semi structured interviews and the observations were references to children and illustrations of challenges within the work place. The details of the stories corresponded to the focus of the lecture. There did appear to be a pattern in the generation of stories. The specific request from tutors for examples would usually lead to a story. The telling of one story often stimulated the telling of another (table 1) supporting the idea that stories are often swapped as part of normal human interaction (McDrury and Alterio, 2002, Schank, 1995).

The lectures focussing on risk and challenge instigated the most stories. These lectures did cover unusual situations and events that disrupted the day to day routine such as an emergency. This links to the theory of Bruner (1987) and Ricoeur (1990) that stories often feature the disruption and subsequent restoration of the status quo.

\section{Theme two: Interesting stories held meanings for individuals}

The most common reason given for an interesting story within this study was that individuals felt they could identify with the situation. Effective stories held meaning for the individual. Examples included problem-solving, the perception of increased knowledge, and an emotional connection such as

163 J. of Practice Teaching \& Learning 13(2-3), pp.146-168. ( $w \mathcal{E} b$ 
empathy around a similar struggle. Valuable stories also provided pleasure in the form of humour. All participants connected the skills of the storyteller to the quality of a story mainly through the storyteller's ability to deliver the traits participants most associated with an engaging story such as meaning and humour. Two students described the storyteller as a messenger. The interviewees recognised that some people were better storytellers than others. This has relevance for group members as the ability to tell a good story has been associated with empowerment. Interestingly quality stories were also seen to require some credibility. This appears inconsistent with the understanding exhibited by participants that stories shared were not always completely factual.

The possible explanation for this is that the accounts of experience and practice shared by tutors and students in higher education are recognised as stories. People can see an account as a story through its narrative content (Bruner, 1987; Ricoeur, 1990). This may encourage the students to as Moon stated "suspend their disbelief" (2010:63). The result is that students are satisfied in the credibility of a story if it felt believable rather than if it was true. It is acknowledged that stories blur between fact and fiction (Ricoeur, 1990; Moon and Fowler, 2008). Therefore it may not always be necessary to extract the truth from every story shared as the value of the story is mainly in its meaning.

Limitations: this study is based on a relatively small sample and provides qualitative insights. The findings are not necessarily generalizable to all students. For example none of those involved in this study were new to practice therefore all participants had a repository of stories for possible sharing. It would be useful to explore the contribution of storytelling to the learning experience of novice practitioners.

\section{Conclusion and recommendations}

The study demonstrated that early years students recognised that story and storytelling within higher education provided numerous benefits to their learning.

There were specific roles attributed to story and storytelling including the facilitation of learning. Particular contributions of story here included easing transfer of knowledge, making lectures more memorable and abstract concepts easier to understand usually by connecting to the listener's own internal experience, their cognitive structure (Moon, 2010). The other roles

164 J. of Practice Teaching E Learning 13(2-3), pp.146-168. ( wEb 
given to story and storytelling included the capacity of storytelling to provide relaxation within the learning environment, entertainment and pleasure. Students perceived a link between story, storytelling and reflective practice. Both pre-planned and spontaneous story was thought to stimulate and enhance reflective thinking. These responses are significant, they suggest that spontaneous storytelling where one story stimulates another should not be dismissed as just conversation occurring for purely cathartic purposes.

The study identified three ways that story and storytelling impacted on social activity within the classroom. Story was seen to facilitate group cohesion. Story contributed to, reinforced and disseminated professional culture. Here the study illustrates how cultural expectations and imagination can impact on reality in practice through story sharing. Story was also seen to have some influence on the direction of learning.

A story's capacity to engage a listener was usually attributed to an individual's ability to make a connection to the story. As not everyone will connect to every single story there are implications for storytelling management. The skills of the storyteller were also associated with the quality of the story. This result promotes the idea that effective storytelling should be practiced and developed particularly as storytelling was also linked to empowerment.

Recommendations resulting from this study include support for the formal recognition of storytelling within higher education particularly for those courses linked to practice. This would include facilities that promote storytelling such as small group learning. The study recommends that tutors are trained in understanding the value of storytelling particularly spontaneous storytelling that could be dismissed as chatter. Tutors also need to be skilled in the management of storytelling. Given the strong association between story and empowerment tutors should encourage students to develop their storytelling skills.

\section{References}

Alterio, M. (2004) Collaborative journalling as a professional development tool. Journal of Further and Higher Education, 28, 3, 321-332

Bain, J. Ballantyne, R. Packer, J. and Mills, C (1999) Using journal writing to enhance student teachers' reflectivity during field experience" Teachers and Teaching. 5, 1, 51-73 
Bell, J (2010) Doing your research project; A guide for first time researchers in education, health and social science. Maidenhead, McGraw-Hill Open University Press

Boje, D. (1991) The storytelling organisations a study of performance in an office supply firm. Administrative Science Quarterly, 36, 1, 7-17

Bond, A. (ed.), 2006) Your masters thesis; How to plan, draft, write and revise. Abergele: Study Mates Limited

Boud, D. and Walker, D. (1993) Barriers to reflection on experience. in D. Boud, R. Cohen, and D. Walker (Eds.) Using experience for learning. Buckingham: SRHE and Open University Press

Braun,V. and Clarke, C. (2006) Using thematic analysis in psychology. Qualitative Research in Psychology, 3, 77-101

Bruner, J. (1986) Actual minds, possible worlds. London: Harvard University Press Bruner, J. (1987) Life as narrative. Social Research, 54, 1, 11-32

Bruner, J. (1990) Acts of meaning. London, Harvard University Press

Bruner, J. (1991) The narrative construction of reality. Critical Inquiry, 18, 1, 1-21

Chan, E. A. \& Chung, L.Y.F. (2004) Teaching abstract concepts in contemporary nursing through spirituality. Reflective Practice, 5, 1, 125-132

Clough, P. and Nutbrown, C. (2007) A students guide to methodology. London: Sage

Cohen, L. Manion, L. and Morrison, K. (2000) Research methods in education. (5thed.) London: Routledge Falmer

Douglas, K. and Carless, D. (2009) Exploring taboo issues in professional sport through a fictional approach. Reflective Practice 10, 3, 311-323

Drever E. (2003) Using semi structured interviews in small scale research: A teacher's guide. Glasgow: The Scottish Council for Research in Education

Frid, I., Öhlén, J. and Bergbom, I. (2000) On the use of narratives in nursing research. Journal of Advanced Nursing, 32, 3, 695-703

Fund, Z. Court, D. \& Kramarski, B. 2002. Construction and application of an evaluation tool to assess reflection in teacher training courses. Assessment and evaluation in higher education. 27, pp.485-499

Gabriel, Y. (2000) Storytelling in organisations. Oxford, Oxford University Press

Gibbs, G. (1988) Learning by doing: a guide to teaching and learning methods. London, F.E.U

Gold, J. and Holman, D. (2001) Let me tell you a story: an evaluation of the use of storytelling and argument analysis in management education. Career Development International, 6, 7, 384-395

Harrison, K. (2009) Listen: this really happened: making sense of social work through story telling. Social Work Education, 28, 7, 750-764

Kolb, D. (1984) Experiential learning: experience as the source of learning and development. Englewood Cliffs, N.J.: Prentice Hall

166 J. of Practice Teaching \& Learning 13(2-3), pp.146-168. @ wE-b 
Lieberman, M. (2007) Social cognitive neuroscience: A review of core processes. Annual Review of Psychology 22, 415-450

Marton, F. and Booth, S. (1997) Learning and awareness. Hillsdale N.J.: Lawrence Erlbaum Associates. Cited in: Moon, J. (2010) Using story in higher education and professional development. London: Routledge

McDrury, J. and Alterio, M. (2002) Learning through storytelling: Using reflection and experience in higher education contexts. Palmerston North New Zealand, The Dunmore Press

McEwan, H. and Egan, K. (1995) Narrative in teaching, learning and research. New York: Columbia University, New York Teachers College

Moon, J. and Fowler, J. (2008) There is a story to be told: A framework for the conception of story in higher education and professional development. Nurse Education Today, 28, 2, 232-239

Moon, J. (2010) Using story in higher education and professional development. London: Routledge

Morgaine, C. (1999) Alternative paradigms and professionalizing childhood care and education: the Oregon example. Child Youth Care Forum, 28, 5-19

Noddings, N. (1996) Stories and affect in teacher education. Cambridge Journal of Education 26, 3, 435-448

Nutbrown, C. (2012) Review of early education and child care qualifications: Interim report. London: Department of Education available from <http: www.education.gov.uk> [Accessed 1.6.2012]

Propp, V. (1968) Morphology of the folktale. Austin: University of Texas Press

Ricoeur, P. (1984) Time and narrative volume 1. Chicago: The University of Chicago Press

Ricoeur, P. (1990) Time and narrative volume 3. Chicago: The University of Chicago Press

Robson C. (2002) Real World Research: A resource for social scientists and practitioner researchers. (2nd ed.) Oxford: Blackwell

Saxe, R. and Wexler, A. (2005) Making sense of another mind: The role of the right tempero-parietal junction. Neuropsychologia, 43 , 1391-1399

Schank, R. (1995) Tell me a story. Evanston IL.: North Western University Press Schein, E.H. (1987) Defining organizational culture. in J. Shafritz and S. Ott (Eds..) Classics of organizational theory (2nd ed.) Chicago: The Dorsey Press. Cited in Bellot, J. (2011) Defining and assessing organizational culture. Nursing forum 46, 1, 29-37

Schön, D. (1983) The reflective practitioner. San Francisco: Jossey Bass

Silverman, D. (2006) Doing qualitative research. 2nd ed. London, Sage Publications Taylor, C. (2006) Narrating significant experience: Reflective accounts and the

167 J. of Practice Teaching \& Learning 13(2-3), pp.146-168. @ wEb 
production of (self) knowledge. British Journal of Social Work. 36, 189-206

Taylor, S. Fisher, D. and Dufresne, R. (2002) The aesthetics of management storytelling. Management Learning, 33, 3, 313-330

Walliman, N. (2005) Your research project. (2nd ed.) London: Sage

Webster, L. and Mertova, P. (2007) Using narrative inquiry as a research method: an introduction to using critical event narrative analysis in research on learning and teaching. London: Routledge

White, J. (1991) War stories: invitations to reflect on practice. in: R. Tabachnick and K. Zeichner (Eds.) Issues and practices in inquiry orientated teacher education. London: Falmer Press

Wilkinson, D. (Ed.) (2000) The researcher's toolkit: The complete guide to practitioner research. London: Routledge Falmer

Wooffitt, R. (1992) Telling tales of the unexpected: The organisation of factual discourse. Hemel Hempstead: Harvester Wheatsheaf

Yin R. (2003) Case study research design and methods. (3rd ed.) London: Sage 